Conclusion: This series of refractory FMF patients with potentially higher inflammatory characteristics showed COVID-19 did not result in a worse outcome in those patients during the first phase of the pandemic, and none developed findings of cytokine storm. Observations in these patients supports further that biologic agents blocking IL-1 and possibly TNF may contribute to the uneventful course of COVID-19 by preventing the development of hyperinflammatory response. Data collection from a larger group of patients, especially those with amyloidosis, will clarify the protective effects of colchicine and contribution of anti-IL-1 treatments on the favourable disease course during the second phase of the pandemic.

\begin{tabular}{|c|c|c|c|c|c|c|c|}
\hline & Patient 1 & Patient 2 & Patient 3 & Patient 4 & Patient 5 & Patient 6 & Patient 7 \\
\hline $\begin{array}{l}\text { Age (years) } \\
\text { MEFV } \\
\text { variants }\end{array}$ & $\begin{array}{c}45 \\
\text { Unknown }\end{array}$ & $\begin{array}{c}48 \\
\mathrm{M} 694 \mathrm{~V} \\
\text { /M680I }\end{array}$ & $\begin{array}{c}39 \\
\text { Unknown }\end{array}$ & $\begin{array}{c}53 \\
\text { M694V/ } \\
\text { M694V }\end{array}$ & $\begin{array}{c}32 \\
\text { M694V/ } \\
\text { M694V }\end{array}$ & $\begin{array}{c}37 \\
\text { M694V/ } \\
\text { M694V }\end{array}$ & $\begin{array}{c}31 \\
\text { M694V/ } \\
\text { M694V }\end{array}$ \\
\hline Amyloidosis & No & No & No & No & No & No & No \\
\hline $\begin{array}{l}\text { Biologic } \\
\text { agents }\end{array}$ & $\begin{array}{c}\text { Anakinra } \\
100 \mathrm{mg} / \\
\text { day }\end{array}$ & $\begin{array}{l}\text { Not taken } \\
\text { for } 1 \\
\text { year }\end{array}$ & $\begin{array}{c}\text { Adalimu- } \\
\text { mab }\end{array}$ & $\begin{array}{c}\text { Canakinumab } \\
150 \mathrm{mg} / \\
\text { month }\end{array}$ & $\begin{array}{c}\text { Anakinra } \\
100 \mathrm{mg} / \\
\text { day }\end{array}$ & $\begin{array}{c}\text { Canakinumab } \\
150 \mathrm{mg} / \\
\text { month }\end{array}$ & $\begin{array}{c}\text { Anakinra } \\
100 \mathrm{mg} / \\
\text { day }\end{array}$ \\
\hline $\begin{array}{l}\text { Prednisone } \\
\text { (mg/day) }\end{array}$ & 5 & No & No & No & No & No & No \\
\hline $\begin{array}{l}\text { Colchicine } \\
\text { (mg/day) }\end{array}$ & 2 & 1,5 & 1,5 & 1,5 & 1,5 & 2,0 & 2,0 \\
\hline $\begin{array}{l}\text { RT-PCR } \\
\text { positivity }\end{array}$ & Yes & Yes & Yes & Yes & Yes & Yes & Yes \\
\hline $\begin{array}{c}\text { Chest CT } \\
\text { signs }\end{array}$ & Yes & Yes & Not done & Not done & Not done & Not done & Not done \\
\hline Hospitalisation & No & No & No & Yes & No & No & No \\
\hline $\begin{array}{l}\text { Antiviral } \\
\text { therapy }\end{array}$ & Oseltamivir & Oseltamivir & No & Favipravir & Favipravir & Favipravir & Favipravir \\
\hline HCQ use & Yes & Yes & Yes & Yes & No & No & No \\
\hline $\begin{array}{l}\text { New FMF } \\
\text { attack } \\
\text { during } \\
\text { COVID-19 }\end{array}$ & No & No & No & No & No & No & No \\
\hline
\end{tabular}

Disclosure of Interests: None declared

DOI: 10.1136/annrheumdis-2021-eular.3903

\section{POS1260 FACTORS ASSOCIATED WITH SEVERE SARS-COV-2 INFECTION IN PATIENTS WITH INFLAMMATORY RHEUMATIC DISEASES IN MADRID: RESULTS FROM REUMA-COVID SORCOM REGISTRY}

A. Boteanu ${ }^{1}$, A. García Fernández ${ }^{1}$, N. De la Torre ${ }^{2}$, M. Pavia Pascual ${ }^{2}$ O. Sanchez Pernaute ${ }^{3}$, S. Recuero Diaz ${ }^{3}$, S. Perez Esteban ${ }^{3}$, G. Bonilla ${ }^{4}$, L. Nuño ${ }^{4}$, J. J. Sanmartin Martinez ${ }^{5}$, C. Bonilla Gonzalez-Leganá ${ }^{6}$, D. Clemente Garulo $^{7}$, L. Lojo Oliveira ${ }^{8}$, J. M. Rodríguez Herredia ${ }^{9}$, J. Bachiller-Corral' ${ }^{1}$ on behalf of REUMA-COVID SORCOM. ${ }^{1}$ H. U. Ramón y Cajal, Rheumatology, Madrid, Spain; ${ }^{2}$ H.U. Puerta de Hierro, Rheumatology, Madrid, Spain; ${ }^{3}$ H.U Fundación Jiménez Diaz, Rheumatology, Madrid, Spain; ${ }^{4}$ H.U La Paz, Rheumatology, Madrid, Spain; ${ }^{5}$ H.U Severo Ochoa, Rheumatology, Madrid, Spain; ${ }^{6}$ H.U del Tajo, Rheumatology, Madrid, Spain; ${ }^{7}$ H.U. Niño Jesus, Rheumatology, Madrid, Spain; ${ }^{8}$ H.U Infanta Leonor, Rheumatology, Madrid, Spain; ${ }^{9}$ H.U. Getafe, Rheumatology, Madrid, Spain

Background: Patients with inflammatory rheumatic diseases (IRD) infected with SARS-CoV-2 may be at risk to develop a severe course of COVID-19 due to the immune dysregulation or the influence of immunomodulating drugs on the course of the infection. For a better understanding of SARS-CoV-2 infections in patients with IRD and due to the high incidence of COVID-19 in Madrid from the beginning of this pandemic infection in Spain, the Society of Rheumatology from Madrid (SORCOM) established a registry (REUMA-COVID SORCOM) shortly after the beginning of the pandemic in Spain.
Objectives: To determine factors associated with severity of infection with SARS-CoV-2 in patients with inflammatory rheumatic diseases in Madrid

Methods: The REUMA-COVID SORCOM registry is a multicenter, retrospective, observational cohort study conducted in Madrid, a SORCOM initiative. All rheumatology departments from Madrid were invited to participate. The study includes patients with IRD presenting with a confirmed or highly suspected diagnosis of COVID-19 between March 1, 2020, and November 10, 2020. We consider severe infection death or need of hospitalization. Inclusion criteria was having an IRD and at least 1 of the following 4 criteria: (1) a biologically confirmed COVID-19 diagnosis based on a positive result of a SARS-CoV-2 polymerase chain reaction (PCR) test on a nasopharyngeal swab; (2) Detection of IgM or IgG anti SARSCoV2 in a symptomatic or asymptomatic patients (3)typical thoracic computed tomography (CT) abnormalities (ground-glass opacities) in epidemic areas; (4) COVID19-typical symptoms in an epidemic zone of COVID-19.

Results: As of November 10,2020, 417 patients with IRD were included in the REUMA-COVID SORCOM registry. 5 patients were discharged for incomplete data. Of 412 patients (mean age 57 years, $87.4 \%$ Caucasian race, $66.3 \%$ female) 174 need hospitalization $(42.2 \%)$ and 33 patients died (18.4\% mortality in hospitalized patients). $82.3 \%$ had comorbidities. 234 (56.8\%) patients were classified as inflammatory arthropathy, $133(32.3 \%)$ had connective tissue diseases (CTD) $41.1 \%$ of the patients had a large history of IRD (> 10 years). $10.4 \%$ of patients had previously pulmonary involvement. The study includes 143 patients taking Methotrexate, 89 patients taking anti-TNF $\alpha$ therapy and 27 Rituximab. In the univariant analysis, no differences were seen in the severity of COVID-19 infection in patients taking methotrexate. $63 \%$ of the all patients taking Rituximab included in the registry need hospitalization and $22 \%$ of them died. Hypertension, COPD or cardiovascular disease was associated with hospitalization.

Independent factors associated with COVID-19 hospitalization in the multivariate analysis was: age ( $>62$ years), male sex, IMC $>30$, previous cardiovascular comorbidities and the IRD disease duration ( $>10$ years). Independent factors associated with COVID-19 related death was: age ( $>62$ years), having a CTD diagnose, pulmonary involvement before infection and chronical GC treatment. Conclusion: Patients with IRD represent a population of particular interest in the pandemic context because the baseline immunological alteration and the treated with immunosuppressants agents they receive, comorbidities and the well-known risk of severe infection. Older age, male sex, cardiovascular comorbidities were factors associated with high risk of hospitalization in IRD patients. CTD diseases, previously pulmonary involvement and chronical GC treatment with more than $10 \mathrm{mg} /$ day were associated with high risk of death. Neither ant TNF- $\alpha$ treatment nor Methotrexate were risk factor for hospitalization or death COVID-19 related in IRD patients.

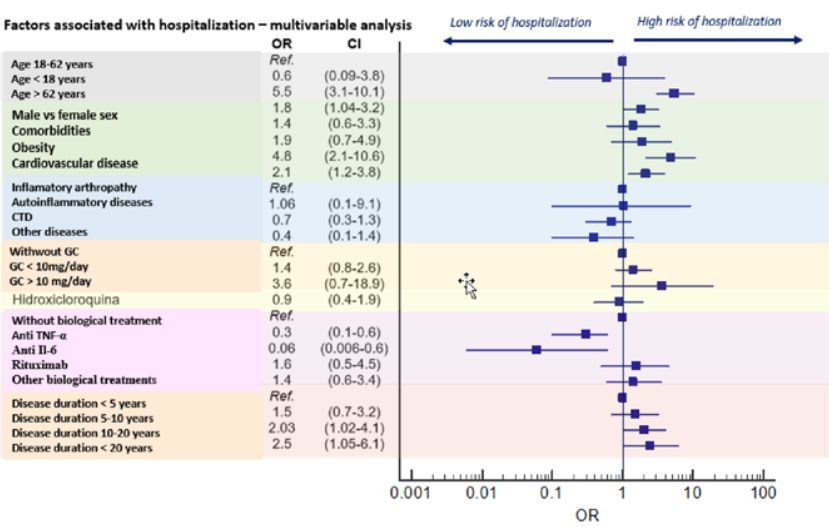

Disclosure of Interests: None declared DOI: 10.1136/annrheumdis-2021-eular.3973 